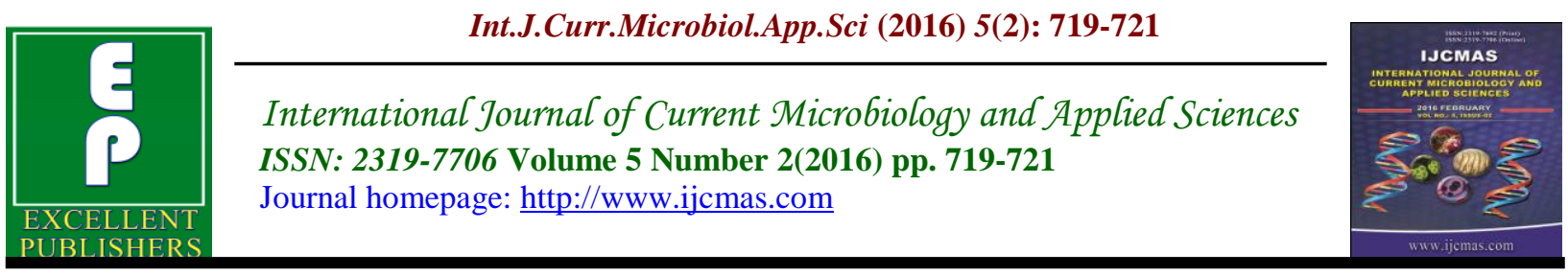

Original Research Article

doi: http://dx.doi.org/10.20546/ijcmas.2016.502.080

\title{
A Case of Cellulitis Due to Double Invasive Infection by Escherichia hermanii and Klebsiella pneumoniae
}

\author{
Gaurav Salunke ${ }^{1 *}$ and Amit Mandhare ${ }^{2}$ \\ ${ }^{1}$ Department of Microbiology, B.K.L. Walawalkar Rural Medical College, Dervan, Chiplun \\ (Taluka), Ratnagiri (District), Maharashtra. 415606 \\ ${ }^{2}$ Department of General Surgery, B.K.L. Walawalkar Rural Medical College, Dervan, Chiplun \\ (Taluka), Ratnagiri (District), Maharashtra. 415606 \\ *Corresponding author
}

\begin{abstract}
A B S T R A C T
Keywords

E. hermannii and Klebsiella pneumonia, Cellulitis Due to Double Invasive Infection

Article Info

Accepted:

28 January 2016 Available Online: 10, February 2016

Cellulitis is an inflammatory condition of the skin and subcutaneous tissue, characterized by erythema, swelling, warmth, and pain. The etiologic agents are most often Streptococcus pyogenes and Staphylococcus aureus, followed by non-group A $\beta$-hemolytic streptococci and gram-negative bacilli 1 Although Escherichia hermannii (E. hermannii); a gram negative rod shaped bacterium has occasionally been described as an opportunistic human pathogen, there is evidence in the literature to demonstrate that some strains contain determinants of pathogenicity. We report the first case of cellulitis co infected with E. hermannii and Klebsiella pneumonia ( $K$. pneumonia). No prior antibiotic were started, confirming the invasiveness and pathogenic potential of the microorganisms.
\end{abstract}

\section{Introduction}

In November 2015, a 55 years old male patient was referred to the Surgical OPD at B.K.L. Walawalkar Rural Hospital, Dervan with complaint of swelling of right leg since 10 days. The swelling was more in the lower part of the leg (below the knees). He had developed cellulites and there was oozing of pustular discharge from the leg. He had not taken any antibiotics for the cellulites. The patient was a known case of alcoholic liver disease with no history of Diabetes, Hypertension or any recent trauma.
On Examination, findings were remarkable for a fever of $39.3^{\circ} \mathrm{C}$, a heart rate 90 beats/min, a respiratory rate $22 / \mathrm{min}$, a blood pressure of 138/84 $\mathrm{mmHg}$, and somnolence. On physical examination swelling of right leg below the knees was seen and pitting oedema + . The skin over the lower leg was discoloured (dark) and there was an erythematous, inflamed patch over the lower portion of the legs with some oozing. There was tenderness ++ of the affected part with warmth ++. Laboratory testing showed a 
white blood cell count of $5400 / \mathrm{ml}$ with $69.6 \%$ neutrophils and $31.4 \%$ lymphocytes. $\mathrm{X}$ ray and venous doppler of the limb was unremarkable. All the findings were suggestive of cellulitis.

Surgical debridement was done and pus was sent to the microbiology department for gram staining and culture. Gram staining revealed the presence of pus cells and Gram negative rods. Antibiotic regimen was started with high dose Piperacillin/ Tazobactum for broad base coverage.

The culture plate after 24 hours grew two types of Gram-negative rods; one was a lactose fermenter and other with yellow colony pigmentation. It was identified by MicroScan (Siemens) rapid Gram-negative panel. The cultures were finally identified as $K$. pneumoniae ( $99.9 \%$ probability) and $E$. hermannii (99.99\% probability) on the basis of colony pigmentation and chemical reactions to glucuronic acid, arabinose, inositol, ornithine, glucose, alpha-l-glutamic acid, 1-pyroglutamic acid, and tryptophan. $K$. pneumoniae was sensitive to Amikacin, Gentamicin, Imepenem, Levofloxacin, Meropenem, Piperacillin/Tazobactum, Tetracycline and Tigecycline. E. hermanii was sensitive to Amikacin, Amoxicillin/Clavulinic Acid, Cefoxitin, Imipenem, Levofloxacib, Meropenem, Tetracycline, and Tigecycline.

The antibiotic coverage was then altered to Amikacin and Levofloxacin. After regular dressings and antibiotics, the patient's symptoms improved. He was discharged on hospital day 6 and completed a 2-week antibiotic course with oral Levofloxacin. The patient has been followed up for past 1 month and has been doing well.

We report the first case of cellulitis of poly microbiological etiology due to $\mathrm{K}$. pneumonia and E. hermannii in our hospital.
Cellulitis is a common medical emergency, the severity of which varies from mild to life threatening. The infection can occur on any body site; lower limbs are affected in $\leqslant 70 \%$ of cases. ${ }^{1}$ Although less commonly isolated, gram negative organisms may be more involved in infections among immunocompromised patients. Polymicrobial invasive infections are infrequent, representing $<10 \%$ of the invasive infections of known etiology. ${ }^{2}$ They are often correlated with a predisposing factor: immunodeficiency (e.g., diabetes mellitus, malignancies, extremes of age) or use of a central catheter. ${ }^{3}$ Patients with alcoholic liver disease display immune responses consistent with those observed in immunocompromised individuals and alcohol is a potent immunosuppresor. ${ }^{4}$ Cellulitis in lower limb, in a patient with alcoholic liver disease, due to double invasive infection by $\mathrm{E}$. hermanii and $K$. pneumoniae (gram negative organisms) clearly emphasizes the invasive and pathogenic potential of the isolated organisms.

In humans, E. hermanii has been sporadically recovered from clinical specimens such as wound specimens, sputum, and stools. ${ }^{5-8}$ It usually produces wound or gastrointestinal tract infections. K. pneumonia is found in the normal flora of the mouth, skin, and intestines. ${ }^{9}$. In our patient, both E. hermanii and K. pneumonia must have probably originated from the skin or from the gastrointestinal tract.

Infections involving $E$. hermannii as the putative primary pathogen are very rare, and occur in individuals predisposed to infection or involve a significant breach in normal barriers against infection. The majority of case reports involving $E$. hermannii were polymicrobial with other known humanpathogenic bacteria, e.g., methicillinsusceptible Staphylococcus aureus (MSSA) 
and Leclercia adecarboxylata, and the other micro-organisms involved were considered to be the primary pathogens. Therefore E. hermanii has also been considered as an associated pathogen. ${ }^{5} 6$ In this case, E. hermanii was isolated in large numbers. Hence it being an associated pathogen is less likely.

In vitro studies have found that $E$. hermannii produces $\beta$-lactamase and exhibits a distinctive antibiotic resistance pattern, with resistance to Penicillin, Ampicillin, and Carbenicillin. Resistance to Amoxicillin is reversible if Amoxicillin is administered in combination with the $\beta$-lactamase inhibitor clavulanate. ${ }^{10}$ In our case the E. hermannii showed sensitivity towards Amikacin, Amoxicillin/Clavulinic Acid, Cefoxitin, Imipenem, Levofloxacin, Meropenem, Tetracycline, and Tigecycline. We selected Amikacin and ciprofloxacin for their in vitro effectiveness against the two pathogens.

In our case, although the pathogenicity of $E$. hermannii remains undetermined, it can be considered a primary pathogen as it been isolated in large numbers. Further studies need to be done to identify the pathogenic determinants of the organism. The combined medical and surgical intervention allowed for a successful outcome in this invasive infection.

\section{References}

1. Carratalà J, Rosón B, Fernández-Sabé N, et al. Factors associated with complications and mortality in adult patients hospitalized for infectious cellulitis. Eur J Clin Microbiol Infect Dis 2003; 22: 151-7

2. Ruiz-Giardin JM, Noguerado A, Pizarro A, Mendez J, La Hulla F, Fernandez M, et al. Comparative study of prognostic and risk factors for mortality in polymicrobial bacteremia-fungemia in a university hospital: development over 10 years. Enferm Infecc Microbiol Clin. 2002;20:435-42

3. Calvet HM, Yoshikawa TT. Infections in diabetes. Infect Dis Clin North Am. 2001;15:407-21

4. Song K, Zhao X, Marrero L, Oliver P, Nelson S, Kolls JK.. Alcohol reversibly disrupts TNF- $\alpha /$ TACE interactions in the cell membrane. Respir Res. 2005; 6: 123

5. de Baere T, Wauters G, Huylenbrock A, Claeys G, Peleman R, Verschraeger G, et Al . Isolations of Leclercia adecarboxylata from a patient with a chronically inflamed gallblader and from a patient with sepsis without focus. $J$ Clin Microbiol. 2001;39:1674-5

6. Dahl KM, Barry J, De Biasi RL. Escherichia hermanii infection of a cephalohematoma: case report, review of literature and description of a novel invasive pathogen. Clin Infect Dis. 2002;35:e96-98.

7. Poulou A, Dimitroulia E, Markou F, Tsakris A. Escherichia hermannii as the sole isolate from a patient with purulent conjunctivitis. $J$. Clin. Microbiol. 2008; 46: 3848-9.

8. Popescu GA, Daha I, Popescu C, Mitache E. Staph. aureus and Escherichia hermannii in diabetes patient. Emerg. Infect. Dis. 2004;10:1335-7.

9. Ryan, KJ; Ray, CG, eds.2004. Sherris Medical Microbiology (4th ed.). McGraw Hill.

10. Stock I, Wiedemann B. Natural antibiotic susceptibility of Escherichia coli, Shigella, E. vulneris and E. hermannii strains. Diagn. Microbiol. Infect. Dis.1999. 33:187-99.

\section{How to cite this article:}

Gaurav Salunke and Amit Mandhare. 2016. A Case of Cellulitis Due to Double Invasive Infection by Escherichia hermanii and Klebsiella pneumoniae. 2016. Int.J.Curr.Microbiol.App.Sci. 5(2): 719-721. doi: http://dx.doi.org/10.20546/ijcmas.2016.502.080 